\title{
Kernos
}

Revue internationale et pluridisciplinaire de religion grecque antique

5 | 1992

Varia

\section{L.P. GERSON, God and Greek Philosophy. Studies in Early History ofNatural Theology}

Éveline Loucas-Durie

(2) OpenEdition

Journals

Édition électronique

URL : http://journals.openedition.org/kernos/1076

DOI : 10.4000/kernos.1076

ISSN : 2034-7871

\section{Éditeur}

Centre international d'étude de la religion grecque antique

Édition imprimée

Date de publication : 1 janvier 1992

ISSN : 0776-3824

\section{Référence électronique}

Éveline Loucas-Durie, «L.P. GERSon, God and Greek Philosophy. Studies in Early History ofNatural Theology », Kernos [En ligne], 5 | 1992, mis en ligne le 16 juin 2011, consulté le 25 septembre 2020. URL : http://journals.openedition.org/kernos/1076 ; DOI : https://doi.org/10.4000/kernos.1076

Kernos 
Roland CRAHAY, La religion des Grecs, Bruxelles, Éd. Complexe, 1991, 1 vol. $11,5 \times 17,5 \mathrm{~cm}, 180 \mathrm{p}$.

Cet ouvrage est la réédition du petit livre publié voici 25 ans dans la collection «Problèmes» chez Labor. On y retrouve, mise à jour et plus agréablement présentée 1 , la même anthologie raisonnée où prennent place les plus grands textes de la tradition religieuse. D'Homère à Dion Chrysostome et à Grégroire de Naziance, en passant par Hérodote, Platon, Démosthène, Euripide, les Orphiques, etc., nous voyons s'édifier sous nos yeux tout un corpus, bien connu en ces textes, lui servant de matériaux, mais saisissant de clarté par l'ordonnance et la composition.

Rien n'y est négligé du sentiment religieux, des phénomènes de croyance, - populaire ou littéraire, - des rites, des comportements sociaux, majoritaires ou non. Peut-être les lieux de culte sont-ils quelque peu oubliés, mais il suffira à cet effet de se reporter à l'ouvrage de Marie Delcourt, Les grands sanctuaires de la Grèce antique, récemment réédité par Gérard Monfort (1982). Rappelons que Roland Crahay fut son élève, et que c'est à elle qu'il emprunte sa traduction des textes d'Euripide; tous les autres extraits ont fait l'objet d'une version française originale, neuve et irréprochable.

Pierre SOMVILLE (Liège)

L.P. GERSON, God and Greek Philosophy. Studies in Early History of Natural Theology, London-New York, Routledge, 1990, 1 vol. 14 x $22 \mathrm{~cm}$, 340 p. (Issues in Ancient Philosophy, gen. ed. M. Schofield)

Cet ouvrage est une manifestation typique de l'esprit analytique de la recherche anglo-saxonne. Il se divise en cinq chapitres, traitant successivement des "origines présocratiques de la théologie de la nature» (p. 1-32), de «Platon sur dieu et les formes» (p. 33-81), du "dieu mouvement d'Aristote» (p. 82-141), de "la théologie matérialiste stoïcienne" (p. 142-184) et de "Plotin sur dieu au-delà de dieu» (p. 185226). Bien qu'on puisse regretter l'absence de présentation de la sophistique, on se réjouira des réflexions de l'A. commençant par l'analyse de la notion d'«archè» (p. 5-14), pour aboutir à la relation étroite entre l'Un, archè de tout, et le "nous» (p. 221-238). Parmi les chapitres intéressant l'historien de la religion, on mentionnera ceux sur la forme du dieu chez Platon (p. 57-66), sur le rapport entre dieu, causalité et être chez Aristote (p. 134-141) et sur les arguments des Stoïciens concernant l'existence de dieu (p. 154-167). L'A. aborde également la question de

1 Petite remarque iconographique : le «Zeus» en p. 1 de couverture pourrait bien être un Poseidon .... 
l'attaque de Sextus Empiricus contre la théologie dogmatique, et traite avec beaucoup de finesse des problèmes concernant la pensée théologique de Plotin.

Le livre comporte une bibliographie (p. 311-324), un index général (p. 325-332), ainsi qu'un index des textes cités (p. 333-340).

Éveline LOUCAS-DURIE (Athènes)

Pierre HADOT, Plotin. Traité 50 (III, 5). Introduction, traduction, commentaire et notes, Paris, Éd. du Cerf, 1990, 1 vol. 12,5 x 19,5 cm, 291 p. (Coll. Les écrits de Plotin publiés dans l'ordre chronologique sous la direction de Pierre Hadot). ISBN : 2-204-04135-1. Prix : 140 FF.

Cet ouvrage est le deuxième d'une collection qui s'attache à fournir au public une traduction des œuvres de Plotin (cf. Kernos, 1 [1988], p. 253, pour le compte rendu du premier volume). Le traité 50 du philosophe pose la question de savoir si l'Amour - Éros - est un Dieu, un démon ou un état de l'âme. Partant des mythes du Banquet de Platon concernant les deux Aphrodites et la naissance d'Éros, de même que de considérations du Phèdre, Plotin propose un exercice d'exégèse allégorique qui lui permet «d'amener l'âme à découvrir que ce qui fait naître en elle l'Amour, c'est à la fois la présence et l'absence du bien en elle» (p. 21).

Pour l'historien de la religion grecque, cette œuvre est une illustration intéressante de l'utilisation de mythes parmi les plus anciens et les plus connus des Grecs par une pensée philosophique qui y décèle un certain nombre de réalités métaphysiques qu'il s'agit de traduire. Dans le cas présent du thème de la double Aphrodite, "ouranienne» et "pandémienne», P. Hadot a également montré, dans un bref appendice, l'influence du traité 50 de Plotin sur la pensée et l'art de la Renaissance. Ainsi voit-on Botticelli et le Titien, puisant aux sources antiques par l'intermédiaire de Marsile Ficin et de Pic de la Mirandole, offrir l'image d'une "Vénus" dont la conception se trouve davantage chez Plotin que dans la Théogonie hésiodique.

Soulignons enfin que ce petit ouvrage est remarquablement écrit et que la traduction élégante du traité en rend l'abord très agréable.

\section{Vinciane PIRENNE-DELFORGE (Liège)}

Greg R. STANTON, Athenian Politics c. 800-500 B.C. A Source Book, London-New York, Routledge, 1990, 1 vol. 13,5 x 21,5 cm, 226 p.

Le développement politique et l'évolution sociale de la démocratie athénienne pendant la période archaïque sont le sujet de cet ouvrage. L'«Attique d'avant Solon», «Solon», «De Solon à Pisistrate», «la tyran- 